\title{
Combined efforts to develop students experimental competences
}

\author{
Natércia Lima, Gustavo Alves, Clara Viegas \\ School of Engineering - Polytechnic of Porto \\ Porto, PORTUGAL \\ $\{\mathrm{nmm}, \mathrm{gca}, \mathrm{mcm}\} @$ isep.ipp.pt
}

\author{
Ingvar Gustavsson \\ Blekinge Institute of Technology \\ Karlskrona, SWEDEN \\ ingvar.gustavsson@bth.se
}

\begin{abstract}
Students experimental competences are of most importance in engineering courses. However in post-Bologna courses, the number of contact hours and the actual extent of hands-on lab work were substantially reduced. Online resources usage (simulators and remote labs) has been growing up in the last decades, as more complex and versatile tools are being developed. Unfortunately, several of these usages reported in literature do not show the didactical backing that support these implementations. This work is a step forward, explaining how a teacher implemented a combination of online resources in order to develop experimental competences. The results show significant correlations between students' usage of these resources and their calculus competences and final achievements.
\end{abstract}

Keywords-Hands-on Laboratory, Remote Laboratory, Computer Simulation, Experimental Competence Development, Engineering Education

\section{INTRODUCTION}

Engineering higher education has been engraved with innumerous changes in the last decades. One of these changes is the frequent use of Learning Management Systems (LMSs) and Massive Open Online Courses (MOOCs) as new strategies for reaching tens of thousands students at a time [1]. Additionally, a broader access to online laboratory environments intends to aid students in developing their experimental competences, fundamental in science and engineering [2], [3], [4]. Remote and simulated laboratories have been suffering technological growths and developments, which have been providing more offers intending to fulfil these requirements.

Even though there is still some controversy in its efficacy in general [5], [6], [7], [8] teachers are tending to use it more often, either instead or as a complement to the traditional hands-on lab. Three factors also contributed to the growth of this usage: i) the growth of the number of students, specially a few decades ago; ii) the Bologna reform and the reduced amount of contact time between teachers and students [3]; and, iii) the more limited budget Universities have, which leads to too large classes and to very limited time for each student to really operate in laboratory with the equipment (too large groups implies that not everyone gets the chance to perform real work) [9].

However, this technology usage is still a step away from the didactic effort needed to maximize the potential of these tools.
On their own, these tools might even be prejudicial, since in some cases they are too complex and not automatically understandable to students, leading them to frustration and dropping out of the task [7].

In this paper we will show how a teacher developed a didactical strategy in order to support students learning of electrical circuits. This work intends to compare students' perceptions of their learning and the real work developed while they are exposed to different methods and experimental resources (either compulsory - in classes, or willingly - online). In section II it is explained in more detail the need for a didactical work of preparation in order to get the most of these online lab resources. In section III it is presented the research design used in this work and in section IV and V the results gathered and the conclusion.

\section{DIDACTIC BACKGROUND}

Experimental competences are fundamental in an engineer formation, however the time available both in the course curricula and in the labs occupation tends to be too short. Students need time to overcome their difficulties on their own in order to be able to scaffold their own knowledge construction [10]. The few hours available in hands-on labs does not allow for the majority of students to accomplish that task. In order they are able to finish the programmed work, some teachers tend to facilitate students' work by giving them some "lab recipes" (a set of precise instructions they have to carry out, almost without thinking). This way, students are able to perform the necessary measurements and hopefully figure it out afterwards. However, a great amount of students do not learn in this way, and lab class can be a total waste [4].

Online labs (remote and simulated labs) can be a way to partially overcome this lack of time and resources. However, teachers must know how to wisely use these tools. Their integration in the curriculum must serve a didactical purpose. Teachers need to identify the goals students need to achieve, and then plan tasks with those tools that will allow their development. Those tasks should let students into developing epistemic competences helping them in achieving deeper knowledge and extend their expertise [11].

There are several studies, in literature about online environments usages, but few cover their didactical preparation 
or students achievements [12]. In order to help other teachers, this didactical development should be presented. In this way, teachers might have a more informed way of making decisions about the usage of these tools in specific moments, according to their needs. Stating what works rather well and what does not, in particular and detailed circumstances, can certainly help others to potentiate their effort to make the same mistakes.

In this line of thought, this study intends to share a didactical design of an introductory electricity course, in which the teacher made an effort of incorporating not only these experimental practices but also the calculus of more theoretical problems. The first part of this implementation (Direct Current (DC) circuits) was already presented in a conference [13]. This work presents the results obtained in more challenging tasks, dealing with Alternate Current (AC) circuits. This didactic design (elaborated by the teacher, based on his experience of over 20 years) considered that students should split their attention into several resources. It is now presented the summary of the teacher plan for the curriculum. This is focused on four key aspects of a didactical design: Learning Objectives; Curriculum Implementation; Resources; Teacher Mediation and Students Assessment.

\section{A. Learning Objectives}

Students had already worked DC circuits (first part of the semester, for a period of 6 weeks), using the same resources that will be described hereafter. In the second part of the semester, students learning objectives were related to $\mathrm{AC}$ circuits: Resistor Inductor (RL), Resistor Capacitor (RC), and Resistor Inductor Capacitor (RLC) series and parallel circuits experimental and calculus practice. It was intended that they developed experimental skills of: (1) assembling circuits in a solderless breadboard; (2) using two new measurement devices, i.e. the function generator and the oscilloscope; and (3), using the multimeter (already used in the 1st part of the semester), now in AC mode. Because AC circuits calculus imply using vector and complex numbers notations, the reduced time available for covering this syllabus item implies not solving any AC circuit using Kirchhoff laws, i.e. only simple, series and parallel circuits with one single-frequency power supply are covered both in theoretical and practical classes.

\section{B. Curriculum Implementation}

The implementation was done within a course entitled "Electricity" with 5 ECTS in 2013/14, part of the 1st-year, 2ndsemester of a 3-years degree on Automotive Engineering ${ }^{1}$, following the Bologna model (180 ECTS).

The course had 79 students enrolled, distributed by 3 Laboratory Classes (PL) classes. A total of 63 students (80\%) attended the first assessment test (compulsory) related to DC circuits. So, at most, only these students were attending classes in the second part of the semester.

\section{Resources}

This course was developed based on the usage of several different resources, with the main goal of helping students to develop experimental skills and competences. The teacher imposed the problem resolution using four different resources: calculus, hands-on lab, Falstad circuit simulator [14] and Virtual Instrument Systems in Reality (VISIR) remote lab (in this case two remote labs were used - one from Porto (ISEP) and one from Sweden (BTH)) [3]. These resources were used simultaneously in different class (according to the plan in TABLE I). In terms of contact hours with students, teacher had 3 hours (hr) per week: $1 \mathrm{hr}$ of recitation class (hereafter called $\mathrm{T}$ class), and $1 \mathrm{hr}+1 \mathrm{hr}$ of calculus practice class immediately followed by lab class (hereafter called PL class), during the last 6 weeks of the semester, in the sequence explained in TABLE I.

TABLE I. CLASSES SEQUENCE

\begin{tabular}{|c|c|c|}
\hline \multirow{2}{*}{ 芭 } & \multicolumn{2}{|r|}{ Course Class Planning } \\
\hline & Type & Summary \\
\hline 1 & $\begin{array}{l}\text { T } \\
\text { Explanation } \\
\text { visualization } \\
\text { Falstad } \\
\text { simulator }\end{array}$ & $\begin{array}{l}\text { Introducing inductors (L) and capacitors (C). } \\
\text { Analyzing RL and RC circuits in series, in DC mode: stable } \\
\text { and transient responses. } \\
\text { Time analysis of an RLC resonant circuit (response to a } \\
\text { pulse voltage). }\end{array}$ \\
\hline 2 & $\begin{array}{l}\text { PL } \\
\text { Falstad circuit } \\
\text { simulator and } \\
\text { VISIR remote lab } \\
\text { Room: } \\
\text { Computer room }\end{array}$ & $\begin{array}{l}\text { Training with periodic signals (sine, triangular and square } \\
\text { waves) and its most common parameters: frequency, } \\
\text { period, positive and negative peak values, peak-to-peak, } \\
\text { mean or DC component, duty-cycle, RMS, and form factor. } \\
\text { Visualizing waves and performing measurements in VISIR } \\
\text { and in the Falstad simulator, using the function generator } \\
\text { and the oscilloscope. } \\
\text { Defining the signal parameters with the function generator } \\
\text { (VISIR) and in the simulator, and observing / measuring } \\
\text { them with the oscilloscope (VISIR) and the oscilloscope } \\
\text { channel viewer (simulator). }\end{array}$ \\
\hline & $\begin{array}{l}\mathbf{T} \\
\text { Recitation }\end{array}$ & $\begin{array}{l}\text { Mesh and nodal analysis methods for DC linear electric } \\
\text { circuits. The case of circuits with (voltage and current) } \\
\text { controlled power sources. }\end{array}$ \\
\hline \multirow[b]{2}{*}{3} & $\begin{array}{l}\text { PL } \\
\text { Hands-on lab }\end{array}$ & $\begin{array}{l}\text { Hands-on with the function generator and the oscilloscope. } \\
\text { Visualizing and performing measurements in an RC circuit } \\
\text { in series (Ut, Ur, and Uc). }\end{array}$ \\
\hline & $\begin{array}{l}\text { T } \\
\text { Calculus and } \\
\text { visualization in the } \\
\text { Falstad circuit } \\
\text { simulator }\end{array}$ & $\begin{array}{l}\text { Characterization (calculus and simulation) of RL and RC } \\
\text { circuits in series and parallel. Cross-comparison. }\end{array}$ \\
\hline \multirow{2}{*}{4} & $\begin{array}{l}\text { PL } \\
\text { Calculus }\end{array}$ & $\begin{array}{l}\text { Solving calculus exercises with RLC circuits in series, } \\
\text { parallel, and mixed. }\end{array}$ \\
\hline & $\begin{array}{l}\mathbf{T} \\
\text { Demostration }\end{array}$ & $\begin{array}{l}\text { Demonstrating in class how to perform and cross-compare } \\
\text { results from calculus, simulation and remote } \\
\text { experimentation of an RC circuit in series. }\end{array}$ \\
\hline \multirow{2}{*}{5} & $\begin{array}{l}\text { PL } \\
\text { Hands-on lab }\end{array}$ & Hands-on with RC and RL circuits in series and parallel. \\
\hline & $\mathbf{T}$ & Conclusion. \\
\hline 6 & Assessment & Individual lab assessment. \\
\hline
\end{tabular}

The collaboration with BTH was vital to ensure the possibility (with the new relay switching matrix boards) to make any possible connections in very simple RC and RL

\footnotetext{
${ }^{1}$ http://www.isep.ipp.pt/menu/plano_de_estudos.php?id=50\#
} 
circuits, with different component values. The idea was to allow students making errors as in the hands-on lab, without getting warnings.

In these lab classes, students worked with the hands-on lab - different than before, i.e. for DC circuits students used a proprietary board for interconnecting the components and the lab equipment, while for AC circuits, students used a rather universal solderless breadboard --, with the remote lab and with the simulation. Each class had 25-26 students (even though in this second part of the semester they were fewer due to some dropouts), and each hands-on lab group was constituted up to 4 students, since there were only 6 benches - see Fig. 1, composed by an oscilloscope, function generator, digital multimeter, DC power supply, PC (with restricted access to websites, for safety reasons), breadboard, and standard components (resistors, inductors and capacitors), provided by the teacher as needed.

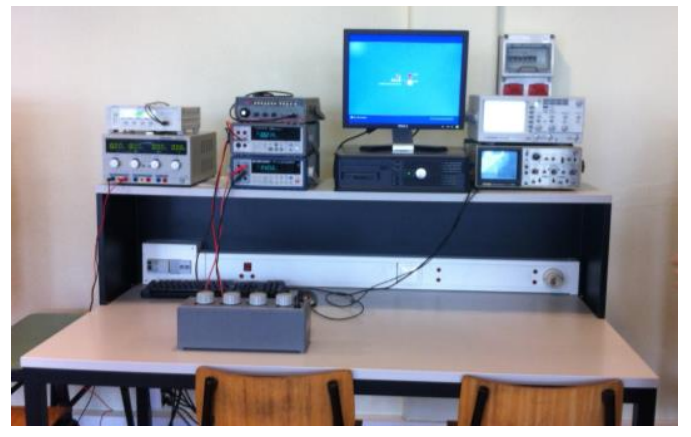

Fig. 1. The hands-on lab bench

During calculus, simulation, and remote lab exercises, students worked in pairs (two students per PC, max.) or as they wished to (individually or larger groups), as they could use their own laptops or tablets.

Teacher also established a course in a MOODLE (Modular Object-Oriented Dynamic Learning Environment) platform where students could access class materials, the simulations and the remote labs. It also allowed students to interact with each other and with the teacher, posing questions and clarify their doubts. In some, but rare occasions the teacher talked to students via Skype (see Fig. 2 for one of those examples, where the teacher tries to help a student with VISIR, accessed in BTH).

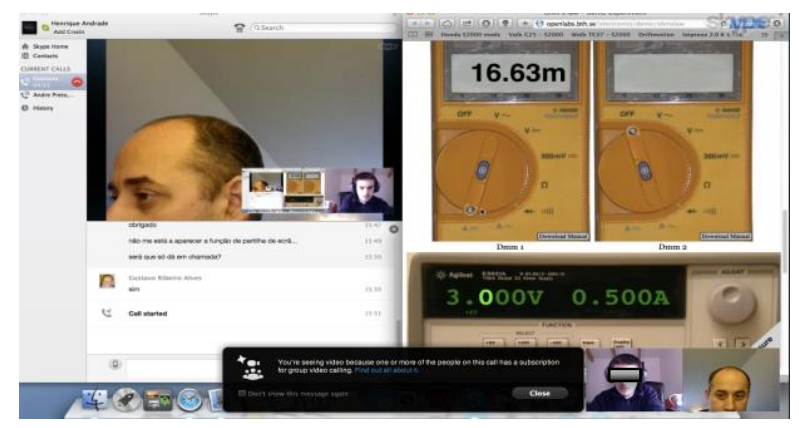

Fig. 2. Example of a Skype meeting between a student and the teacher

\section{Teacher Mediation and Students Assessment}

Teacher tends to have different roles in the distinct kind of classes: in T classes, he was more discursive, but introducing several moments of discussion and exploration of the simulation and/or remote lab (VISIR) in each class. In practicing problems PL class, teacher let students have a predominant role, and try to aid them when they had doubts, with questions intended to help their thought. In lab PL time, teacher proposed the usage of the different resources and work individually in each group of students in each class (in average he spent 5 minutes with each group per class). He encouraged students to develop epistemic work by presenting challenging tasks and by asking for additional aspects in order to help students to go beyond the actual lab experiences. He tried to make students realize that the time spent in lab classes was not enough in order to fulfil most of their necessities in overcoming their difficulties and advised them to work upon the simulation and remote labs. He also warned students that this would be the way they would be assessed (using the different resources).

The assessment test consisted on the analysis of two circuits (see Fig. 3). Students had to use the different resources used during classes (calculus, hands-on lab, simulation and remote lab), evaluating the different competences that were supposedly developed during the course.
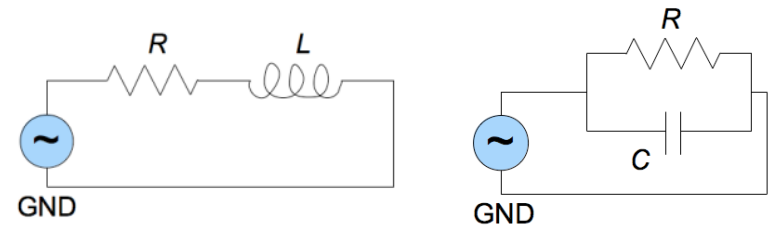

Fig. 3. RL and RC circuits

\section{RESEARCH DESIGN}

\section{A. Problematic and research question}

The problematic tackled in this work is related with the general reduction of laboratory hours in engineering courses and the effects of using some online resources to complement hands-on lab. Since students' experimental skills are fundamental, this lack of contact time in the lab has been complemented with online labs. The research question addressed is "Is the simultaneous usage of different online lab resources useful to support students learning in general and/or for developing their experimental competences?"

\section{B. Research Design}

The chosen method of research was a case study [15], based on the designed course implementation described in the previous sections, which was held at ISEP (Portugal) in the $2^{\text {nd }}$ semester of 2013/14 and involved 1 teacher and 79 enrolled students. This work is based on the second part of the semester, which lasted 6 weeks, where the contents described earlier were developed.

In order to address the research question, students' academic results were crossed with their attendance to class, their accesses to the simulation and remote labs (via Moodle) and their perception of each component value. The statistical methodology used in this work will take the results with 
statistical significance when $\mathrm{p}<0.05$ (at least), meaning a $95 \%$ confidence interval [16].

\section{Collected Data}

The analyzed data consisted of students' assessment results (as a whole and in each component) and their class assistance. These data was accessed for each student.

The number of accesses to classes (students' class attendance), simulator and remote labs was also accessed. The number of accesses to the simulator and remote lab (at ISEP) were measured through the link in the Moodle course. Although we believe most students accessed it via Moodle, this may not be entirely so.

In the end, the teacher delivered a learning perception questionnaire (based in the improved questionnaire for gathering student perceptions of teaching and learning (PLEQ) [17]) that meant to better comprehend their opinion about their learning concerning these different online environments. These data was anonymous.

Finally, the teacher' view was also recorded during a semidirective interview where he shared his experience regarding the design and implementation and also his perception of students understanding and real work developments with each approach.

\section{RESULTS AND ANALYSIS}

\section{A. Class Attending and Test Results}

A total of 55 students $(70 \%)$ attended this compulsory assessment test. The test consisted on the analysis of two circuits: circuit-1 (C1) involved questions using calculus, hands-on and simulation while circuit-2 (C2) included calculus, hands-on and remote laboratory. However due to a problem accessing VISIR while doing the test, most of the students could not complete this component of $\mathrm{C} 2$.

In general, students' performed poorly. Most of the students had bad grades in several resources. Looking at these results per resource it is clear that students performed better in calculus. In fact, calculus in $\mathrm{C} 1$ is the only component that achieved a positive average result (> 50\%). Hands-on lab is where a larger number of students had the worst result, which was indeed very bad.

Comparing the test results with the students' attendance to classes we can infer that the most attending students (zero absences) achieved better results (Fig. 4), even though the results show more dispersion in terms of their final grades. Almost all groups (number of absences) show a positive asymmetric distribution (with mode $>$ median $>$ average).

Similar analyses were performed between: (i) the number of accesses to the simulator (via Moodle) and students' test grade results (total test grade); (ii) the number of accesses to the simulator and the simulator questions grade in the same test), and (iii) the number of accesses to the remote labs and the final grade. Particularly in (ii) results, many outliers were obtained, which means that several students had a very different behavior (Fig. 5).

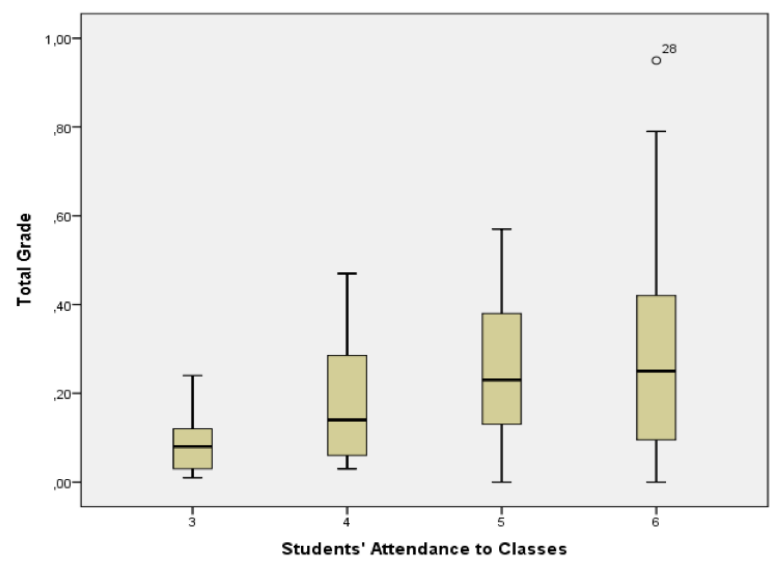

Fig. 4. Boxplot between students' final grade and their class attendance

All these relations suggest that there is a tendency that the more students work with these online resources, better results could be obtained, even though in some students it seems to be the opposite.

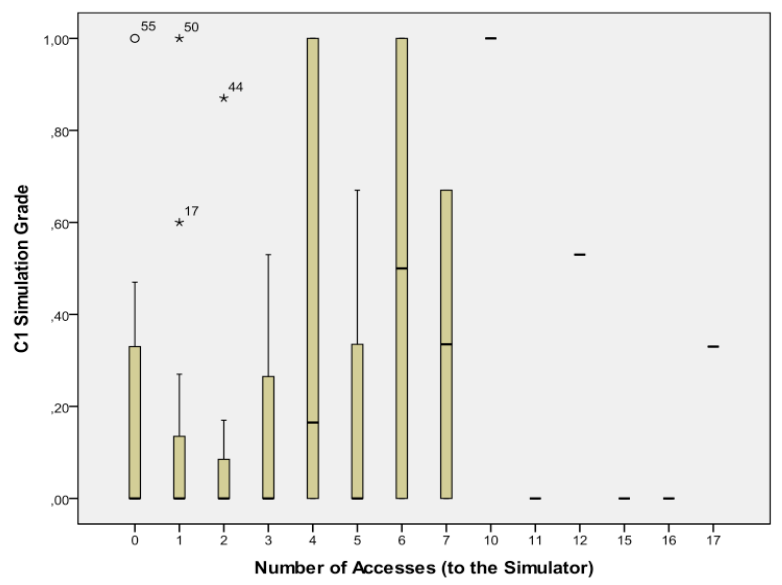

Fig. 5. Boxplot between simulation accesses and its component grade.

In general, analyzing the number of accesses to these online resources (in general, both to simulator and remote labs) and its repercussions on students grade, the obtained relation is shown in Fig. 6. This correlation, even though it is not linear that students with more accesses had better results, there is a tendency to it. Comparing both figures (Fig. 5 and 6) it is also noticeable that students accessed the simulator much more.

The focus of this work is on the usage of different resources. Are their usage significantly correlated with the final grade, or some other component (which could be an indication of some lab competence development)? These analyses are summarized in TABLE II. 


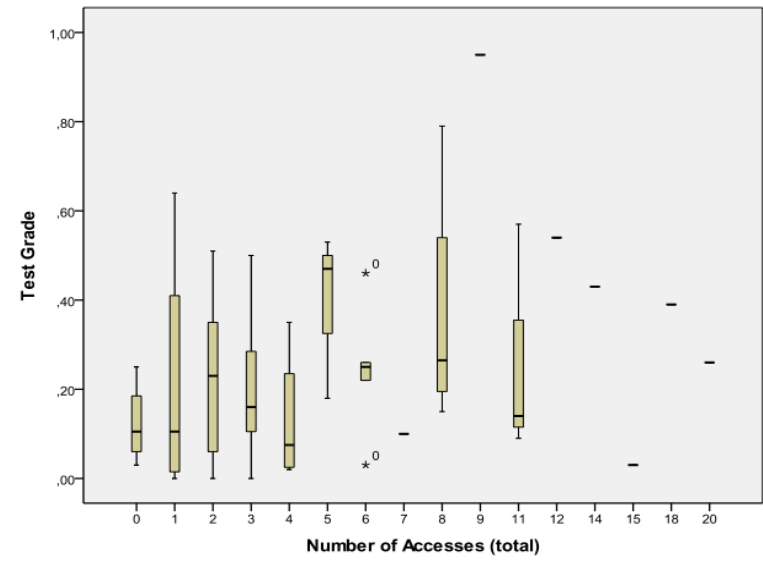

Fig. 6. Boxplot between total number of accesses and final grade

After testing the normality of the variables in study to verify which correlation procedure we could use (Pearson for the ones that follow a normal distribution and Spearman for the others) we performed it for each Group [16]. Since these distributions did not follow normality, the Spearman correlation was performed, relating these variables. The blank spaces mean that there is no significant correlation.

TABLE II. SPEARMAN CORRELATION BETWEEN RESOURCES USAGE AND STUDENTS' GRADES

\begin{tabular}{|l|l|l|l|l|l|l|l|}
\hline $\begin{array}{c}\text { Number of } \\
\text { accesses }\end{array}$ & $\begin{array}{c}\text { C1- } \\
\text { calc }\end{array}$ & $\begin{array}{c}\text { C1- } \\
\text { hands- } \\
\text { on }\end{array}$ & C1-sim & C2-calc & $\begin{array}{c}\text { C2- } \\
\text { hands- } \\
\text { on }\end{array}$ & $\begin{array}{c}\text { C2- } \\
\text { rem }\end{array}$ & $\begin{array}{c}\text { Total } \\
\text { grade }\end{array}$ \\
\hline To class & & & & $0.317^{*}$ & & & $0.278^{*}$ \\
\hline Simulator & & & & $0.314^{*}$ & & & \\
\hline VISIR-ISEP & & & & & & & \\
\hline VISIR-BTH & & & & $0.268^{*}$ & & & $0.273^{*}$ \\
\hline VISIR (total) & & & & & & & $0.325^{*}$ \\
\hline Total & & & & $0.371^{* *}$ & & & $0.306^{*}$ \\
\hline
\end{tabular}

*Correlation is significant at the 0.05 level

**Correlation is significant at the 0.01 level

TABLE II shows a significant correlation between the number of accesses to several resources and the grades obtained namely in $\mathrm{C} 2$-calculus and total test outcome. The work with simulator seems to help students develop important competences in terms of calculus, as the remote labs (especially $\mathrm{BTH}$ ) helped students in a broader manner, helping them achieve better performances in general. These results suggest that some of these online resources did help students to learn, even though it did not guarantee their performance in each component.

For a better understanding if there were significant difference in the results obtained from students who did work with these different online resources and those who did not, the 55 students were split in three groups: Group 1: did not use any resources (8 students); Group 2: just used simulator (9 students); Group 3: used both simulator and remote labs (38 students).
For Group 1 there was not any correlations between the grades and the number of accesses. For Group 2 there was a correlation between the simulation grade obtained in $\mathrm{C} 1$ and the number of accesses to Simulator. As for Group 3 there was a significant correlation both for $\mathrm{C} 2$ calculus grade (significant at the 0,01 level) as well as total test grade (significant at the 0,05 level) with the number of accesses to simulator and the total number of accesses to the online resources.

\section{B. Students Learning Perception}

In order to better understand how students felt about the usage of these different resources, $70 \%$ of the students (55) answered (in class) the questionnaire about their perception of their learning.

As can be observed in Fig. 7, hands-on laboratory is considered, by the majority of the students as the best learning environment, followed by calculus classes. The least interesting learning environment, from students' point of view, is the remote lab; simulation and lectures have similar results.

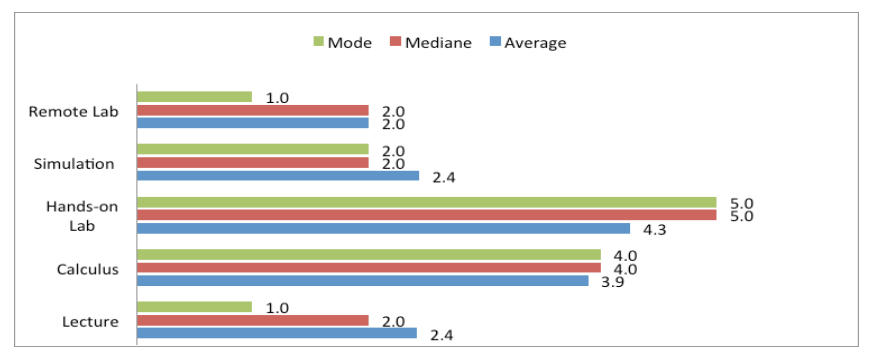

Fig. 7. Results on students perception of the importance of each teaching resource (Likert scale, from 1-5).

Taking into account the type of study and as Fig. 8 shows students prefer equally to study in class or with the help of the teacher; autonomous work appears in the third place and the least interesting type of study is with the computer.

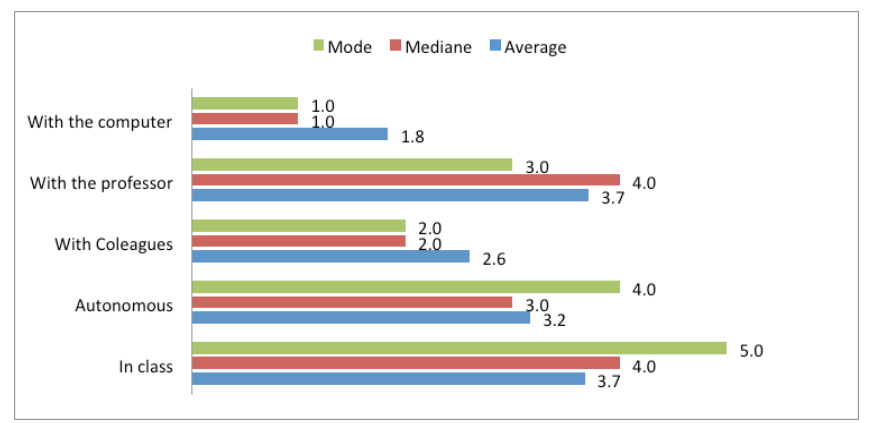

Fig. 8. Results on students preferred type of studies (Likert scale, from 1-5).

The questionnaire also asked them to split the $100 \%$ of the learning responsibility between themselves, teachers, colleagues, other persons and other factors. The results obtained are consistent with the literature and are shown in Fig. 9. They assume that their own responsibility is $47 \%$ and project in others more than $50 \%$ of the responsibility. 


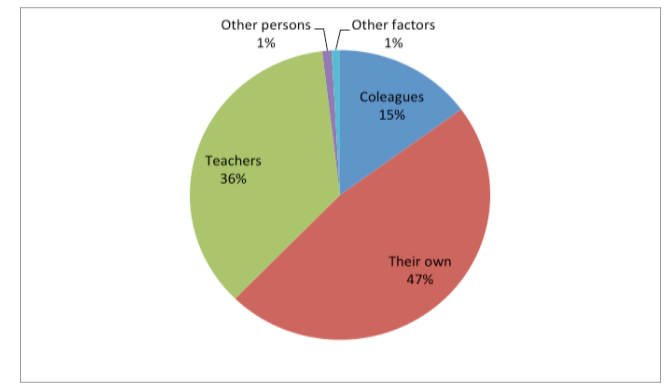

Fig. 9. Results on students learning responsibility distribution

\section{Teacher Perception}

Teacher shared its final perception about students' work, achievements and final results. He thought that this second part of the semester, where more complex epistemic competences had to be developed, was too short in time to overcome students' natural difficulties. Even though there was the same hands-on lab than in the first part of the semester, the fact students had to learn how to use two new equipments (function generator and oscilloscope), with just too many buttons and functions, a new interconnecting board (i.e. the solderless breadboard), and the (more complex) concepts associated with $\mathrm{AC}$ signals and circuits, led to more difficulties.

\section{DISCUSSION AND CONCLUSION}

It has been the understanding of several authors [7], [8], [13] the need for the development of well-designed didactical tasks in order to accompany students in their exploration of these tools and proper feedback in order for them to evolve. With the lack of contact time, students might be overwhelmed if teachers give them too many resources to freely explore. In order to avoid this, in the work presented the teacher tried to scaffold students learning and paths exploring these resources by doing it in class, for students to have a glance of the kind of work they would have ahead. Clearly this did not work for the majority. As argued in literature [4], [10], [11], students should have a primer contact with the tools (with a task development) and then in class, when the teacher works with those resources, students might engage in real work because they already seen it and had doubts.

However, the presented results support stating that the usage of simultaneous online resources might help students dealing with more complex information and prepare them to perform better in other competences areas (in fact all students who performed well are from this group). However not all students evolve the same way, and there are some who seemed to get lost in the resources usage and did not succeed. Nevertheless, the group of students who used these resources (group 3), showed some significant correlations between the number of these accesses and the calculus exercises grade and the total test grades, suggesting that this usage did help them broader in their learning.

As teacher refers, it is extremely difficult to address this complex material in so few classes, and this method of using different online resources simultaneously might be a way to promote better results, with same modifications that were identified.
Finally, answering the research question, the results indicate that students can truly benefit from the usage of online resources to develop their competences in working with and resolving AC circuits problems, namely in the associate calculus. However, it does not show a significant correlation with their experimental expertise.

\section{ACKNOWLEDGMENT}

The authors would like to acknowledge all students who contributed to this work.

\section{REFERENCES}

1. M. Waldrop, The virtual lab, Nature. Vol. 493, pp. 268-270, 2013.

2. C.A. Jara, F.A. Candelas, S.T. Puente and F. Torres, "Hands-on experiences of undergraduate students in Automatics and Robotics". Computer and Education, vol. 57, pp. 2451-2461, 2011.

3. I. Gustavsson, G. Alves, R. Costa, K. Nilsson, J. Zackrisson, U. Hernandez-Jayo and J. Garcia-Zubia, "The VISIR Open Lab Platform 5.0-an architecture for a federation of remote laboratories", REV 2011 8th International Conference on Remote Engineering and Virtual Instrumentation. Brasov, Romania, July 2011.

4. L. Feisel, A. Rosa, "The role of the laboratory in undergraduate engineering education", Journal of Engineering Education, vol. 94(1), pp. 121-130, January 2005.

5. J. Nickerson, J. Corter, S. Esche and C. Chassapis, "A model for evaluating the effectiveness of remote engineering laboratories and simulations in education", Computers \& Education, vol. 49, pp. 708-725, 2007.

6. J. Ma and J. Nickerson, "Hands-On, Simulated, and Remote Laboratories: A Comparative Literature Review”. ACM Computing Surveys, 38 (3). 2006

7. D.C. Sticker, T. Lookabaugh, J. Santos and F. Barnes, "Assessing the effectiveness of remote networking laboratories", $35^{\text {th }}$ ASEE/IEEE Frontiers in Education Conference, Indianapolis, IN, October 2005.

8. Marques, A., Viegas, C., Costa-Lobo, C., Fidalgo, A., Alves, G., Rocha, J. and Gustavsson, I. 2014. How Remote Labs Impact on Course Outcomes: Various Practices Using VISIR. IEEE-Transactions on Education.

9. J.E. Corter, J.V. Nickerson, S.K. Esche, C. Chassapis, S. Im and J. Ma "Constructing reality: A study of remote, hands-on, and simulated laboratories". ACM Transactions on Computer-Human Interaction, vol. 14(2), 2007

10. J.B. Lopes, C. Viegas and J.P. Cravino, "Improving the Learning of Physics and Development of Competences in Engineering Students", International Journal of Engineering Education (IJEE), vol. 26 (3), pp. 612-627, 2010.

11. P. Ramsden, Learning to teach in higher education. New York: Routledge, 1992.

12. D. Lang, C. Mengelkamp, R.S. Jager, D. Geoffroy, M. Billaud and T Zimmer, "Pedagogical evaluation of remote laboratories in eMerge projet", European Journal, vol. 32(1), pp. 57-72, 2007.

13. C. Viegas, N. Lima, G. Alves and I. Gustavsson, "Improving students experimental competences using simultaneous methods in class and in assessments", TEEM'14 Proceedings of the second International Conference on Technological Ecosystems for Enhancing Multiculturality, ACM New York, pp. 125-132, 2014.

14. Paul Falstad, Circuit Simulator Applet, available at http://www.falstad.com/circuit/. Accessed May 15 ${ }^{\text {th }}, 2014$.

15. L. Cohen, L. Manion and K. Morrison, Research Methods in Education, 6th ed., Routledge, Taylor \& Francis Group, London and New York. 2007.

16. W. J. Conover, Practical nonparametric statistics, John Wiley, New York, 1999.

17. M. Devlin, “An improved questionnaire for gathering student perceptions of teaching and learning", Higher Education Research and Development, vol. 21 (3), pp. 289-304, 2002 